Check for updates

Cite this: RSC Med. Chem., 2021, 12 2045

Received 22nd July 2021,

Accepted 5th October 2021

DOI: $10.1039 / \mathrm{d} 1 \mathrm{md} 00248 \mathrm{a}$

rsc.li/medchem

\title{
Investigating 3,3-diaryloxetanes as potential bioisosteres through matched molecular pair analysis $\uparrow$
}

\author{
Maryne A. J. Dubois, ${ }^{a}$ Rosemary A. Croft, ${ }^{a}$ Yujie Ding, ${ }^{\text {a }}$ Chulho Choi, ${ }^{\text {b }}$ \\ Dafydd R. Owen, ${ }^{\mathrm{C}}$ James A. Bull (D) ${ }^{* a}$ and James J. Mousseau*b
}

\begin{abstract}
Oxetanes have received increasing interest in medicinal chemistry as attractive polar and low molecular weight motifs. The application of oxetanes as replacements for methylene, methyl, gem-dimethyl and carbonyl groups has been demonstrated to often improve chemical properties of target molecules for drug discovery purposes. The investigation of the properties of 3,3-diaryloxetanes, particularly of interest as a benzophenone replacement, remains largely unexplored. With recent synthetic advances in accessing this motif we studied the effects of 3,3-diaryloxetanes on the physicochemical properties of 'drug-like' molecules. Here, we describe our efforts in the design and synthesis of a range of drug-like compounds for matched molecular pair analysis to investigate the viability of the 3,3-diaryloxetane motif as a replacement group in drug discovery. We conclude that the properties of the diaryloxetanes and ketones are similar, and generally superior to related alkyl linkers, and that diaryloxetanes provide a potentially useful new design element.
\end{abstract}

\section{Introduction}

The application of bioisosteres to replace problematic functionality is a common strategy in medicinal chemistry. In doing so, the goal is often to maintain target activity and binding kinetics, while simultaneously improving aspects of physicochemical properties and/or improving toxicological profiles. ${ }^{1}$ Synthetic efforts continue to focus on providing new or improved access to novel isosteres, ${ }^{2}$ to both accelerate and improve design options in drug discovery. ${ }^{3}$ The subsequent understanding of the properties of new motifs as well as their effects in a drug discovery setting allows chemical synthesis to have a significant influence in driving novel analogue design. Notable examples include the adoption of sulfoximines ${ }^{4}$ and bicyclo[1.1.1]pentane motifs, ${ }^{2 a}$ as well as oxetanes, ${ }^{5,6}$ each offering attractive physicochemical properties and increased 3-D character.

Studies on oxetanes in medicinal chemistry came to prominence with Carriera's work illustrating the potential of 3,3-disubstituted oxetanes as a replacement group for

\footnotetext{
${ }^{a}$ Department of Chemistry, Molecular Sciences Research Hub, White City Campus, Imperial College London, Wood Lane, London W12 OBZ, UK. E-mail: j.bull@imperial.ac.uk ${ }^{b}$ Medicine Design, Pfizer Worldwide Research, Development and Medical, 445 Eastern Point Rd., Groton, CT 06340, USA. E-mail: james.mousseau@haldathera.com ${ }^{c}$ Pfizer Medicine Design, 610 Main St, Cambridge, MA 02139, USA

$\dagger$ Electronic supplementary information (ESI) available: Spectroscopic data of synthesized compounds, and experimental procedures for ADME data, and table of $\log D$ data. See DOI: 10.1039/d1md00248a
}

gem-dimethyl motifs, and as isosteres for cyclic ketones and morpholines, in spirocyclic examples (Fig. 1). ${ }^{6}$ The incorporation of this polar and low molecular weight moiety has been demonstrated to afford compounds with enhanced properties: improved metabolic stability, solubility and lipophilicity is often observed, while also increasing the $\mathrm{sp}^{3}$ content $\left(\mathrm{Fsp}^{3}\right)$ of a target compound..$^{5-7}$ The ring structure gives the endocyclic oxygen atom increased Lewis basicity and accessibility of the lone pairs, providing hydrogen bond acceptor capability comparable to that of ketones. ${ }^{8}$ Other recent reports include applications as peptidomimetics whereby the carbonyls of amide groups are replaced by

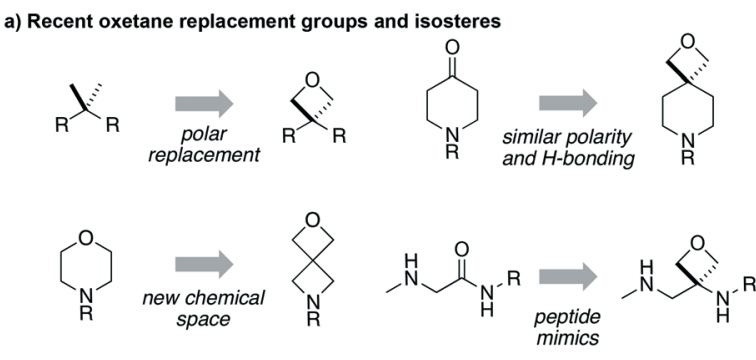

b) This work: Diaryloxetanes as bioisosteres. A matched-molecular pairs study

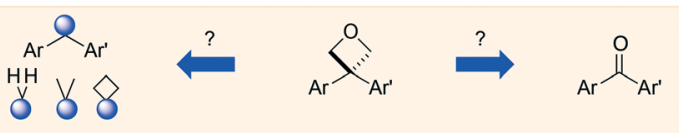

Fig. 1 Developments of oxetane bioisosteres. 
3-aminooxetanes, ${ }^{9}$ as well as oxetan-3-ol as an alternative isosteric replacement of carboxylic acid. ${ }^{10,11}$

3-Mono- and 2-substituted-oxetanes have also seen significant synthetic and medicinal investigation, and are increasingly investigated in SAR studies, and are present in bioactive compounds. ${ }^{5,12,13}$ However, 3,3-disubstituted derivatives have seen the most attention, as they benefit from not introducing a stereocenter, and increase steric protection to avoid ring opening pathways.

We became interested in 3,3-diaryloxetanes as potential bioisosteres for benzophenones that may offer improved properties (Fig. 1b). While benzophenones have been applied to ligate probes in chemical biology applications, ${ }^{14}$ this innate reactivity often makes this highly activated ketone undesirable in medicinal chemistry programs. They often act as photosensitizers, exhibiting phototoxicity through nucleobase modifications. ${ }^{15}$ At Pfizer, as a strategy to mitigate this phenomenon, several internal programs also described a need for 3,3-diaryloxetanes for key analogues. However, mining of internal data demonstrated that this architectural structure was often challenging to access, and as a result attempts towards these design targets were often halted. This was corroborated by a survey of the literature, whereby prior to early 2015 , there were few viable synthetic methods reported towards 3,3-diaryloxetanes. Most relied on the low yielding ring closure of 1,3 -diols, ${ }^{16}$ or a PaternòBüchi cycloaddition, which gave undesired 2,2,3,3tetrasubstituted oxetanes. ${ }^{17}$ Given the knowledge of our internal and external data, we initiated an industrialacademic collaboration between Pfizer and the Bull lab to discover new methods to form these aliphatic heterocycles. This partnership expeditiously developed a new way into 3,3diaryloxetanes through a lithium-catalyzed Friedel-Crafts manifold, which provided unprecedented access to decorated 3,3-diaryloxetane motifs. ${ }^{18}$ Mechanistic understanding enabled the development of other interesting 3,3disubstituted oxetanes. ${ }^{11,19}$ Furthermore, we have been able to demonstrate that 3,3-diaryloxetanes are robust to a range of chemical transformations, enabling access to a range of compounds with diverse functionality.

With these new methods in hand, and cognizant of the lack of understanding of the impact of 3,3-diaryloxetanes on physicochemical properties, we proceeded to a matched molecular pair analysis (MMPA) to probe the effect of replacing a benzophenone with a diaryloxetane on lipophilicity, cell permeability, clearance, solubility, and chemical stability, amongst others. In addition we rationalized that the oxetane could be an effective isostere for metabolically labile diarylmethane groups, as well as lipophilic gem-dimethyl, and cyclobutane derivatives. Herein we disclose our efforts in the preparation of these drug-like compounds as well as the analysis of the subsequent MMPA of physicochemical and biological properties of oxetane, ketone, and other linkers. The aim of this study is to assess the viability of the 3,3-diaryloxetane for putative application in lead optimization in medicinal chemistry settings.

\section{Results and discussion}

Initially, a series of $>150$ lead-like and drug-like compounds was designed targeting properties often desirable in a pharmaceutical setting. ${ }^{20}$ Their properties were predicted with Pfizer's proprietary methods, from which 16 compounds were selected for synthesis with a range of lipophilic values $(\operatorname{cog} D \quad 0.5-5.0)$ as well as eight phenolic precursors to provide a handle for divergent synthesis. Two series were established: 1) the indole series including five linkers (a-e), and 2) the $p$-methoxyphenyl series that constituted oxetaneketone (a,b) pairs (Fig. 2). This provided a comparison of compounds differing by a single structural modification either by the linker in the central carbon or by the $\mathrm{R}$ group.

The synthesis of targets 1a and 2a (Scheme 1a) was achieved via a catalytic Friedel-Crafts alkylation from a readily accessible alcohol precursor, a method developed in our previously disclosed work. ${ }^{18}$ 3-Indolyloxetanol 11a was furnished from commercially available oxetanone and 3-iodomethylindole in the presence of $n$ BuLi. Subjecting oxetanol 11a to a Friedel-Crafts alkylation using $o$-cresol or phenol and an inexpensive lithium triflimide catalyst under mild conditions led to diaryloxetane $\mathbf{5 a}$ in $67 \%$ yield, whereas oxetane $\mathbf{6 a}$ was obtained in $28 \%$. This lower yield was due to the formation of oxetano-ether and dihydrobenzofuran side products consistent with previous work..$^{18,19 a}$

Treatment of arylbromide $\mathbf{1 4}$ with $n \mathrm{BuLi}$ and methylindol3-carboxaldehyde resulted in an unstable alcohol, which after oxidation and deprotection steps gave desired ketone $\mathbf{5 b}$ in $61 \%$ yield over 3 steps (Scheme 1a). The synthesis of compounds $\mathbf{5 c - 5 e}$ was initially attempted using 3-indolylmethanols analogous to oxetanol 11a. However, in contrast to methylindolyl-oxetanol 11a, 3-indolylmethanols 11c and 11e (not shown) were unstable under acidic
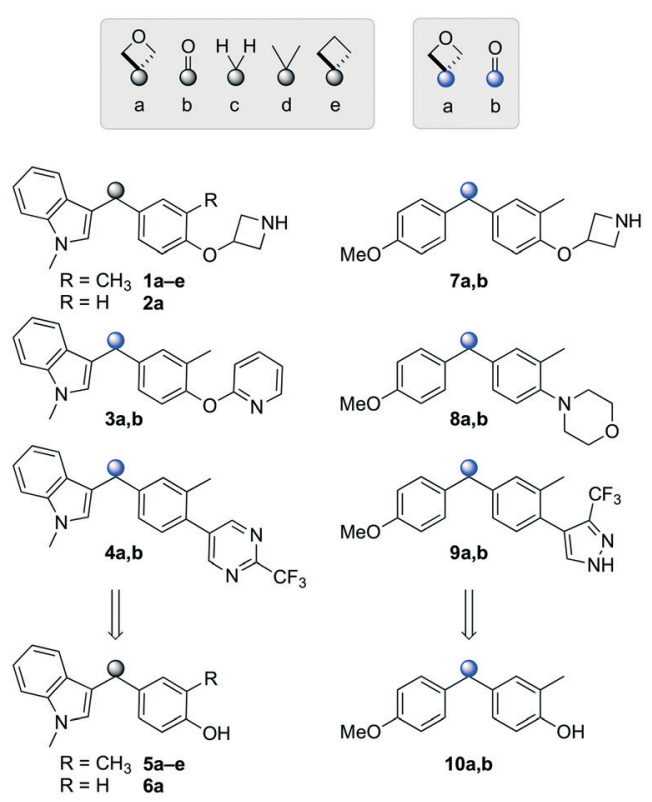

Fig. 2 Compounds selected for the proposed pairwise analysis. 


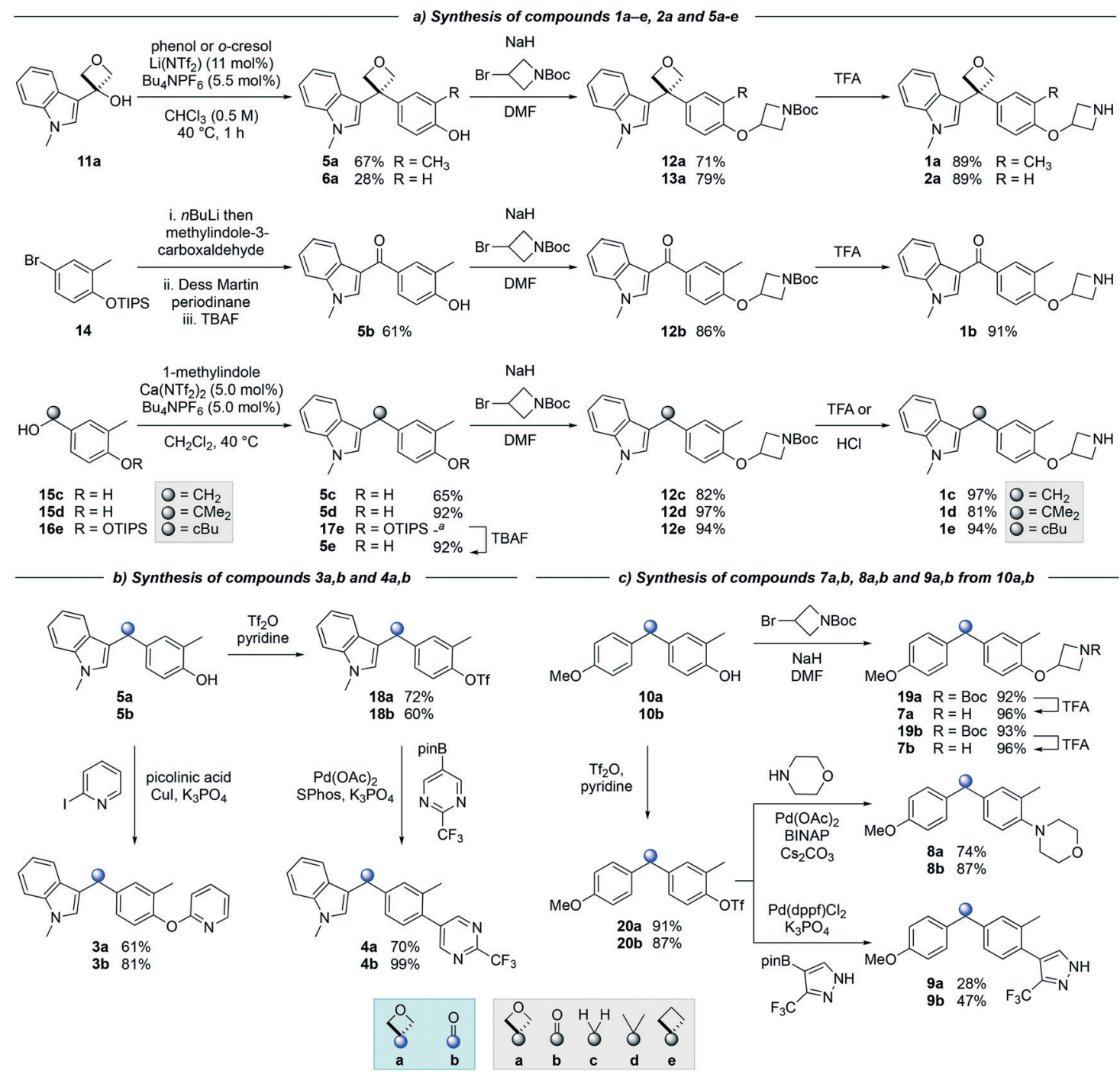

Scheme 1 Synthesis of matched pairs. ${ }^{a}$ Not isolated. Yield of $5 e$ corresponds to yield over 2 steps.

conditions when subjected to the Friedel-Crafts reaction. Dimerization, trimerization, and decomposition of the indolylmethanol precursors were observed (see ESI $\dagger$ ). ${ }^{21}$ Alternatively, Friedel-Crafts alkylation of accessible alcohols $\mathbf{1 5 c}, \mathbf{d}$ and $\mathbf{1 6 e}$ provided access to derivatives $\mathbf{5 c - 5 e}$ (Scheme 1a). Both methylene 5c and gem-dimethyl 5d derivatives were synthesized in good to excellent yields, and cyclobutane $5 \mathbf{e}$ was obtained in $92 \%$ yield after removal of the TIPS protecting group. Interestingly, the calcium triflimide catalyst was found to be more efficient for the synthesis of compounds $\mathbf{5 c}, \mathbf{5 d}$ and $\mathbf{1 7 e}$ relative to the lithium triflimide catalyst which was optimized for the oxetane system. $^{22}$

Alkylation of phenols $5 \mathbf{a}-\mathbf{5 e}$ and $\mathbf{6 a}$ with an $N$-Boc protected azetidine gave ethers $\mathbf{1 2 a}-\mathbf{1 2} \mathbf{e}$ and 13a in excellent yield from $71 \%$ to $97 \%$ (Scheme 1a). Of note, the use of trifluoroacetic acid (TFA) to deprotect the azetidine amines did not lead to ring opening or decomposition of the oxetane ring, delivering both products $1 \mathbf{a}$ and $\mathbf{2 a}$ in excellent yield, and providing further support to the robustness and chemical stability of the 3,3-diaryloxetane motif. Notably, this was in contrast to the gem-dimethyl (1d) and cyclobutane (1e) analogues, which were found to be unstable under these conditions. Instead, $\mathbf{1 d}$ and $\mathbf{1 e}$ were obtained using $\mathrm{HCl}$ in $81 \%$ and $94 \%$ yield respectively. The ketone (1b) and methylene (1c) derivatives were smoothly obtained using TFA. Compounds $\mathbf{1 a}-\mathbf{1 e}$ were made in $20-81 \%$ yield in three to five steps from the corresponding alcohol or bromoarene.

Copper-catalyzed Ullman couplings proceeded with both phenols $\mathbf{5 a}$ and $\mathbf{5 b}$ yielding oxetane $\mathbf{3} \mathbf{a}$ and ketone $\mathbf{3 b}$ in $61 \%$ and $81 \%$ yield respectively (Scheme $1 \mathrm{~b}$ ). The phenols were readily converted to the triflates under standard triflation conditions. Subjecting triflates $\mathbf{1 8 a}$ and $\mathbf{1 8 b}$ to SuzukiMiyaura cross-coupling with a pyrimidine pinacol boronic ester gave both arylated products $\mathbf{4 a}$ and $\mathbf{4 b}$ in $70 \%$ and $99 \%$ yield.

Diaryloxetane 10a was formed using similar conditions as described for $\mathbf{5 a}$, whereas ketone $\mathbf{1 0 b}$ was synthesized via the 
treatment of a Weinreb amide with an aryllithium (see ESI $\dagger$ ). Then, the addition of the $N$-Boc-protected azetidine and subsequent Boc-deprotection was achieved successfully yielding both amines $7 \mathbf{a} / \mathbf{7 b}$ in $96 \%$ yield (Scheme 1c). From triflates 20a and 20b, Buchwald-Hartwig amination gave morpholine substituted oxetane $\mathbf{8 a}$ and ketone $\mathbf{8 b}$ in 74 and $87 \%$ yield respectively. Suzuki-Miyaura cross-coupling afforded biaryl 9a and $9 \mathrm{~b}$ in $28 \%$ and $47 \%$ yield.

With the targets in hand we proceeded with our analysis. Given the common question that arises on the chemical stability of oxetanes, which could preclude application of these motifs in medicinal chemistry programs, we subjected the pairs to a $\mathrm{pH}$ stability assay. Fig. 3 displays selected pairs of ketone/oxetane, as well as the alkyl linkers.

We were pleased to observe that most 3,3-diaryloxetanes were tolerated at low $\mathrm{pH}$, even after $4 \mathrm{~h}$, as well as generally stable at higher $\mathrm{pH}$. The stability of the ketones was similar to oxetanes. While the indole phenol oxetane and ketone 5a and $\mathbf{5 b}$ did demonstrate poorer stability at low $\mathrm{pH}$ (rows 13, 14), this was on par with the corresponding gem-dimethyl (row 17), methylene (row 18) and cyclobutyl (row 20) derivatives, suggesting that the cause of the instability is the designed chemotype and not the linking functional group. Interestingly, removal of the $o$-methyl group on the phenol improved the stability (row 15).

The measured lipophilicity of the oxetane compounds $(\operatorname{elog} D, \mathrm{pH} 7.4)$ was across a range from 1.7-5.1, with an average of 3.4 over 10 compounds, and similar to the calculated values (see $\mathrm{ESI} \dagger$ for full details, as well as $\operatorname{sflog} D$

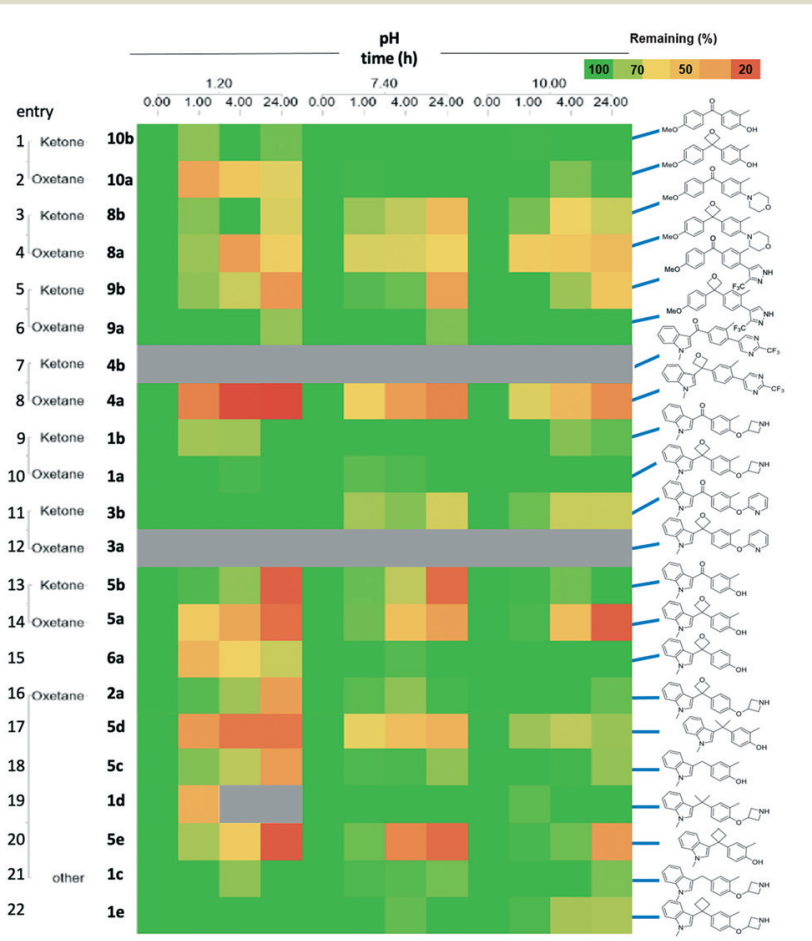

Fig. 3 Stability of selected compounds indicating the \% of compound remaining at different time points across at three different $\mathrm{pH}(1.2,7.4$, 10.0). Grey shading indicates data could not be obtained. data). It was clearly notable that the oxetane led to a significant decrease in measured $\operatorname{elog} D(0.81$ units in $\operatorname{elog} D$ on average) in comparison to each of the methylene, gem-dimethyl, or cyclobutyl analogues, attributable to the polarity of the oxetane. Of particular interest was the effect relative to the corresponding ketone, and we compared five matched pairs. Previous work with other 3,3-disubstituted oxetanes suggested an increase in lipophilicity of 0.1 to 0.7 $\log D$ units. ${ }^{6 b}$ Interestingly, the indole series indicated an average increase of $0.58 \mathrm{log}$ units moving from the ketone to the oxetane (Fig. 4). However, the p-methoxyphenyl series exhibited the opposite trend, whereby the lipophilicity was decreased by $0.30 \mathrm{log}$ units upon incorporation of the oxetane. Although the data disclosed herein suggests that the phenomenon will be series dependent, the combined values infer a similar trend to that reported by Carreira and others with an expected slight $\log D$ increase for the oxetane in comparison to the ketone ( $0.24 \operatorname{elog} D$ units). It is interesting to observe that the trends were similar for measured $\log D$ $(\operatorname{elog} D$ and $\operatorname{sflog} D$ ), whereas calculated $\operatorname{clog} P$ values were routinely higher for the ketone derivatives than the oxetanes (see Table $\mathrm{S} 1 \dagger$ ). An analysis of $\mathrm{H}$-bonding potential may provide further insight but was outside of the scope of this study and was not explicitly assessed. ${ }^{23}$

Clearance by human liver microsomes was generally low to acceptable across the selection of compounds, with the exception of high clearance noted with the phenolic variants. In fact, with the five pairs for which data could be obtained, clearance by human liver microsomes were unchanged between compounds bearing the carbonyl and oxetane groups (Table 1).

Cognizant that the clearance could be driven by $\log D$, and given the similarity of those values between the pairs, a lipophilic metabolism efficiency (LipMetE) analysis was

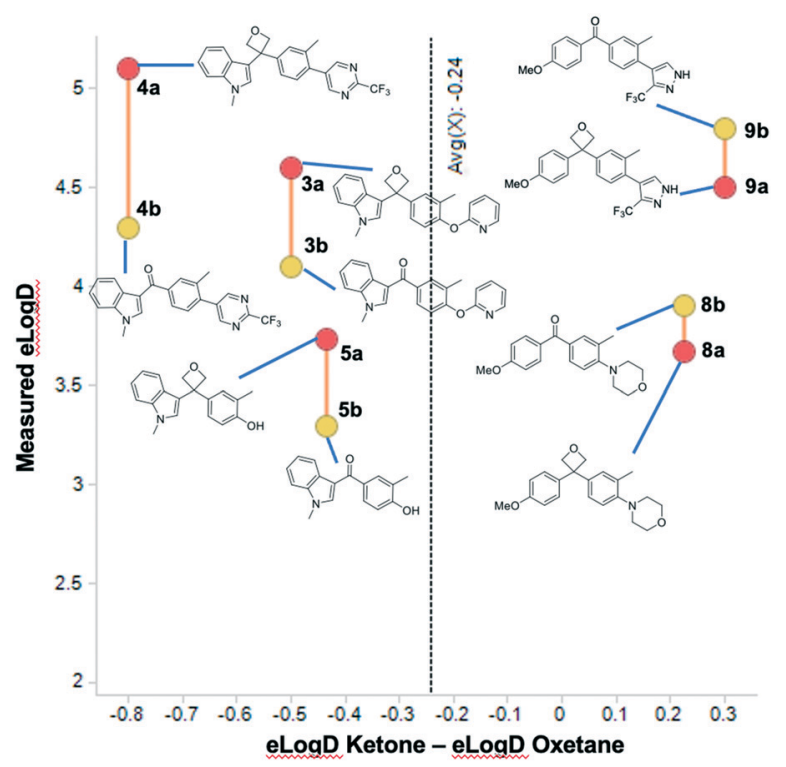

Fig. $4 \log D$ shift of selected compounds indicating the difference between oxetane (red circles) and ketone (yellow circle). 
Table 1 Clearance by human liver microsomes (HLM) of oxetanes vs. ketones

\begin{tabular}{|c|c|c|c|}
\hline Oxetane & HLM Clint $\left(\mu \mathrm{L} \mathrm{min}^{-1} \mathrm{mg}^{-1}\right)$ & Ketone & HLM Clint $\left(\mu \mathrm{L} \min ^{-1} \mathrm{mg}^{-1}\right)$ \\
\hline & 22.9 & & 18 \\
\hline & $<7$ & & $<7$ \\
\hline & 80 & & 77.4 \\
\hline & 7.5 & & 75 \\
\hline & 8.5 & & $<7$ \\
\hline
\end{tabular}

performed. LipMetE is an approach that was put forth in 2013 to describe the efficiency of a compound's metabolic stability relative to its lipophilicity. ${ }^{12 b}$ Seventeen compounds where metabolism and $\log D$ values could be obtained were plotted (Fig. 5). Of the few values obtained with ketones, the LipMetE profile was slightly decreased relative to the oxetane. This could have been expected given the similarity in clearance, and in certain cases, $\operatorname{lower} \log D$ of the ketones. The observation of note was the comparison of oxetanes relative to other linker groups. The majority of the compounds exhibited a LipMetE of $>1$, suggesting that clearance as a function of $\log D$ was favorable for most linkers. The two compounds with values $<1$, while oxetanes, demonstrated low clearance values with acceptable $\log D$ values. The absolute clearance values for some of the nonoxygenated linkers is modest relative to their corresponding $\log D$. This potentially surprising observation is valuable for medicinal chemists as it suggests the possibility of the introduction of 'friendly grease'. It is important to note that there does not appear to be a metabolic liability associated with the 3,3-diaryloxetane motif, and there is an improvement in LipMetE moving from the ketone to the oxetane.

The permeability of the 3,3-diaryloxetanes was universally improved relative to the corresponding methylene, gem-dimethyl and cyclobutyl variants (Fig. 6).

For example, both the methylene and cyclobutyl indolecresol derivatives (5c and $\mathbf{5 e}$ ) were determined to exhibited very poor cell permeability with an RRCK of $0.1 \times 10^{-6} \mathrm{~cm} \mathrm{~s}^{-1}$. When replacing the linker with an oxetane the permeability improved to a very respectable $15.6 \times 10^{-6} \mathrm{~cm} \mathrm{~s}^{-1}$. The conformational constraints between the cyclobutyl and oxetanyl variants would be expected to be similar, and hence the improvement is due to the additional oxygen atom. The ketones were overall found to behave similarly to the oxetanes in cell permeability, with no clear trend when comparing the ketone and oxetanes. In three oxetane/ketone pairs the permeability decreased moving from ketone to oxetane, one pair was unchanged, and two pairs

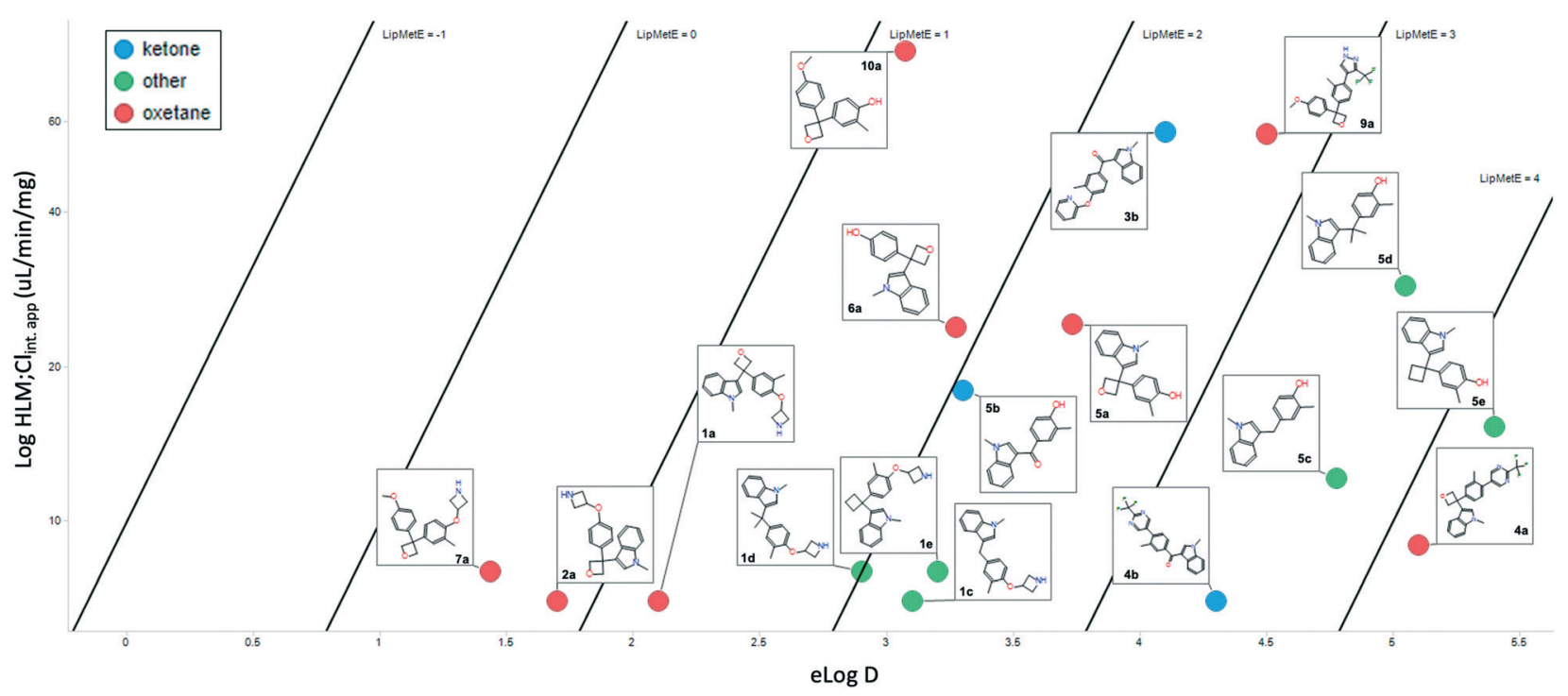

Fig. 5 Lipophilic metabolism efficiency (LipMetE) analysis. 


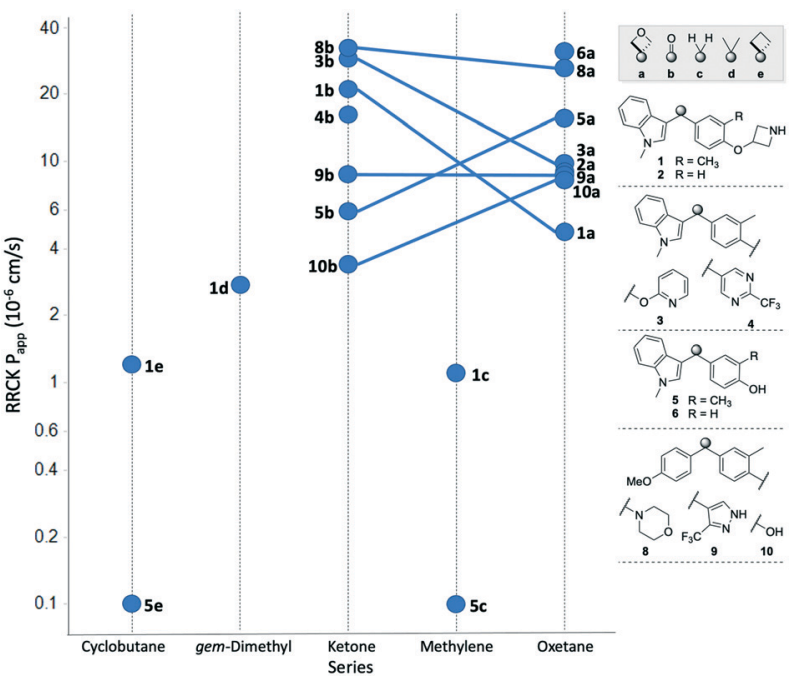

Fig. 6 Comparison of cell permeability across the different linker types. Oxetane/ketone pairs indicated by linking line.

demonstrated improved permeability with the oxetane. This data suggests that the inclusion of an 3,3-diaryloxetane can be a tactic to improve cell permeability relative to the comparable all-carbon derivatives, but does not necessarily equate to an improvement relative to the corresponding benzophenone.

As our last parameter we considered the kinetic solubility of the prepared compounds. The solubility varied significantly based on peripheral structure. ${ }^{24}$ Comparison of the obtained results with the 3,3-diaryloxetanes and the corresponding ketones indicates that the solubility was largely unchanged by the inclusion of the oxetane. While some oxetanes did display improved profiles relative to the their isosteric counterparts (Fig. 7, rows $1 / 2,9 / 10,16$ ), the solubility of the molecules appear to be governed primarily by the aryl components, and as such in these architectures, oxetanes cannot be guaranteed to improve a low solubility profile.

\section{Conclusions}

In summary, we have conducted the first study of the property space of 3,3-diaryloxetanes and related compounds in drug-like space, with direct comparisons to ketone and alkyl variants (methylene, gem-dimethyl, and cyclobutyl derivatives). We observed that the oxetane compounds are chemically stable to a range of $\mathrm{pH}$ and are no more prone to decomposition than other linker motifs. Indeed the oxetane examples showed advantageous stability within the synthetic sequences. The change in lipophilicity profile between oxetane and ketone was not uniform, as certain motifs displayed an increase in $\log D$ while others were lowered. The $\log D$ of the oxetane derivatives was significantly improved in comparison to the carbonlinkers. There was little change in metabolic stability when switching from a ketone to an oxetane, however improved profiles were observed relative to other isosteric equivalents.

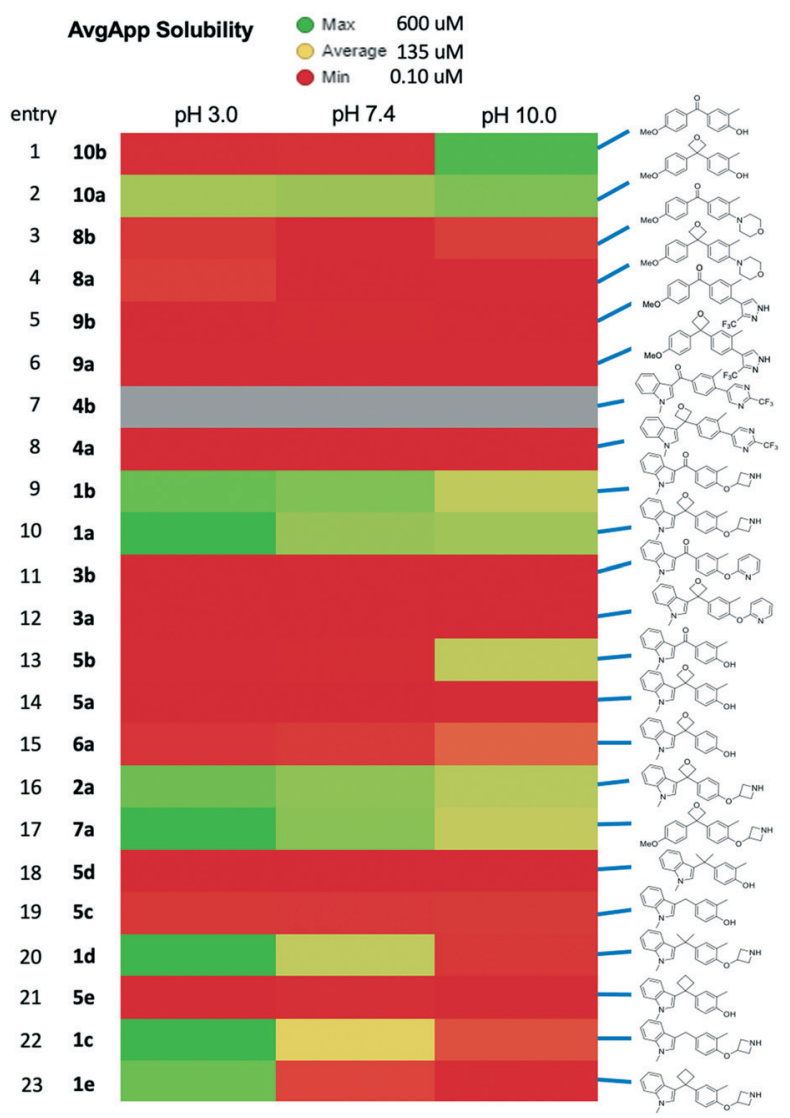

Fig. 7 Comparison of solubility. Kinetic solubility at $3 \mathrm{pH}$ values with color indicating solubility range as indicated.

Cell permeability is markedly improved by changing a methylene, gem-dimethyl or cyclobutane to an oxetane or ketone, however, as with the $\log D$, improvements from ketone to oxetane vary on a case by case basis. Lastly, the inclusion of an oxetane did not reliably improve solubility compared to ketones in these examined series.

Overall, the 3,3-diaryloxetanes displayed similar physicochemical properties to diaryl ketones, without the electrophilic and potential photochemical liabilities, and overall improved properties compared to methylene, gem-dimethyl and cyclobutane analogues. We have also further demonstrated the potential of the catalytic FriedelCrafts methodology from 3-aryloxetan-3-ols to form 3,3diaryloxetanes in compounds with drug-like and lead-like properties. We conclude that the diaryloxetane motif may provide a valuable replacement for diarylketones, as well as for other diarylmethane motifs. Furthermore, we propose that the diaryloxetane unit itself presents an attractive motif in underexplored chemical space that may find broader application in drug discovery as a new analogue design option without intrinsic liabilities.

\section{Conflicts of interest}

There are no conflicts to declare. 


\section{Acknowledgements}

We gratefully acknowledge The Royal Society [University Research Fellowship, UF140161 and URF|R|201019 (to J. A. B.), URF appointed grant RG150444 and URF enhancement grant RGF $|E A| 180031]$, EPSRC [CAF to J. A. B. (EP/J001538/1)], Pfizer for studentship funding (M. D) and Imperial College London for a Presidents Scholarship (R. A. C). Dr. B. Gerstenberger and Dr. J. Montgomery are thanked for their contributions and assistance with visualizations. Dr. M. Perry and Dr. S. Wright are thanked for their input. Dr. Y. Fobian, Dr. D. Hepworth, Dr. D. Blakemore, and Dr. M. Bunnage are thanked for their support.

\section{Notes and references}

1 N. A. Meanwell, J. Med. Chem., 2011, 54, 2529-2591.

2 For selected examples: (a) A. F. Stepan, C. Subramanyam, I. V. Efremov, J. K. Dutra, T. J. O'Sullivan, K. J. Dirico, W. S. McDonald, A. Won, P. H. Dorff, C. E. Nolan, S. L. Becker, L. R. Pustilnik, D. R. Riddell, G. W. Kauffman, B. L. Kormos, L. Zhang, Y. Lu, S. H. Capetta, M. E. Green, K. Karki, E. Sibley, K. P. Atchison, A. J. Hallgren, C. E. Oborski, A. E. Robshaw, B. Sneed and C. J. O'Donnell, J. Med. Chem., 2012, 55, 3414-3424; (b) P. K. Mykhailiuk, Org. Biomol. Chem., 2019, 17, 2839-2849.

3 K. R. Campos, P. J. Coleman, J. C. Alvarez, S. D. Dreher, R. M. Garbaccio, N. K. Terrett, R. D. Tillyer, M. D. Truppo and E. R. Parmee, Science, 2019, 363, eaat0805.

4 (a) P. Mäder and L. Kattner, J. Med. Chem., 2020, 63, 14243-14275; (b) U. Lücking, Org. Chem. Front., 2019, 6, 1319-1324.

5 J. A. Bull, R. A. Croft, O. A. Davis, R. Doran and K. F. Morgan, Chem. Rev., 2016, 116, 12150-12233.

6 (a) G. Wuitschik, M. Rogers-Evans, K. Müller, H. Fischer, B. Wagner, F. Schuler, L. Polonchuk and E. M. Carreira, Angew. Chem., Int. Ed., 2006, 45, 7736-7739; (b) G. Wuitschik, M. Rogers-Evans, A. Buckl, M. Bernasconi, M. Märki, T. Godel, H. Fischer, B. Wagner, I. Parrilla, F. Schuler, J. Schneider, A. Alker, W. B. Schweizer, K. Müller and E. M. Carreira, Angew. Chem., Int. Ed., 2008, 47, 4512-4515; (c) J. A. Burkhard, B. Wagner, H. Fischer, F. Schuler, K. Müller and E. M. Carreira, Angew. Chem., Int. Ed., 2010, 49, 3524-3527; (d) G. Wuitschik, E. M. Carreira, B. Wagner, H. Fischer, I. Parrilla, F. Schuler, M. Rogers-Evans and K. Müller, J. Med. Chem., 2010, 53, 3227-3246.

7 F. Lovering, J. Bikker and C. Humblet, J. Med. Chem., 2009, 52, 6752-6756.

8 M. Berthelot, F. Besseau and C. Laurence, Eur. J. Org. Chem., 1998, 1998, 925-931.

9 (a) N. H. Powell, G. J. Clarkson, R. Notman, P. Raubo, N. G. Martin and M. Shipman, Chem. Commun., 2014, 50, 8797; (b) G. P. Möller, S. Müller, B. T. Wolfstädter, S. Wolfrum, D. Schepmann, B. Wünsch and E. M. Carreira, Org. Lett., 2017, 19, 2510-2513.
10 P. Lassalas, K. Oukoloff, V. Makani, M. James, V. Tran, Y. Yao, L. Huang, K. Vijayendran, L. Monti, J. Q. Trojanowski, V. M. Y. Lee, M. C. Kozlowski, A. B. Smith, K. R. Brunden and C. Ballatore, ACS Med. Chem. Lett., 2017, 8, 864-868.

11 For synthetic studies on thioester isosteres, see: R. A. Croft, J. J. Mousseau, C. Choi and J. A. Bull, Chem. - Eur. J., 2018, 24, 818-821.

12 (a) A. F. Stepan, K. Karki, W. S. McDonald, P. H. Dorff, J. K. Dutra, K. J. DiRico, A. Won, C. Subramanyam, I. V. Efremov, C. J. O'Donnell, C. E. Nolan, S. L. Becker, L. R. Pustilnik, B. Sneed, H. Sun, Y. Lu, A. E. Robshaw, D. Riddell, T. J. O'Sullivan, E. Sibley, S. Capetta, K. Atchison, A. J. Hallgren, E. Miller, A. Wood and R. S. Obach, J. Med. Chem., 2011, 54, 7772-7783; (b) J. E. Dowling, M. Alimzhanov, L. Bao, M. H. Block, C. Chuaqui, E. L. Cooke, C. R. Denz, A. Hird, S. Huang, N. A. Larsen, B. Peng, T. W. Pontz, C. Rivard-Costa, J. C. Saeh, K. Thakur, Q. Ye, T. Zhang and P. D. Lyne, ACS Med. Chem. Lett., 2013, 4, 800-805; (c) P. P. Kung, P. Bingham, A. Brooun, M. Collins, Y. L. Deng, D. Dinh, C. Fan, K. S. Gajiwala, R. Grantner, H. J. Gukasyan, W. Hu, B. Huang, R. Kania, S. E. Kephart, C. Krivacic, R. A. Kumpf, P. Khamphavong, M. Kraus, W. Liu, K. A. Maegley, L. Nguyen, S. Ren, D. Richter, R. A. Rollins, N. Sach, S. Sharma, J. Sherrill, J. Spangler, A. E. Stewart, S. Sutton, S. Uryu, D. Verhelle, H. Wang, S. Wang, M. Wythes, S. Xin, S. Yamazaki, H. Zhu, J. Zhu, L. Zehnder and M. Edwards, J. Med. Chem., 2018, 61, 650-665.

13 Other work suggests 3-substituted oxetanes are not substrates for Phase 2 clearance pathways: (a) F. Toselli, M. Fredenwall, P. Svensson, X.-Q. Li, A. Johansson, L. Weidolf and M. A. Hayes, J. Med. Chem., 2019, 62, 7383-7399; (b) M. A. J. Duncton, M. A. Estiarte, D. Tan, C. Kaub, D. J. R. O'Mahony, R. J. Johnson, M. Cox, W. T. Edwards, M. Wan, J. Kincaid and M. G. Kelly, Org. Lett., 2008, 10, 3259-3262; (c) A. F. Stepan, G. W. Kauffman, C. E. Keefer, P. R. Verhoest and M. Edwards, J. Med. Chem., 2013, 56, 6985-6990.

14 (a) G. W. Preston and A. J. Wilson, Chem. Soc. Rev., 2013, 42, 3289; (b) R. E. Galardy, L. C. Craig, J. D. Jamieson and M. P. Printz, J. Biol. Chem., 1974, 249, 3510-3518.

15 (a) F. Boscá and M. A. Miranda, J. Photochem. Photobiol., B, 1998, 43, 1-26; (b) M. C. Cuquerella, V. Lhiaubet-Vallet, J. Cadet and M. A. Miranda, Acc. Chem. Res., 2012, 45, 1558-1570.

16 B. Hodous, J. L. Kim, K. J. Wilson, D. Wilson and Y. Zhang, Compositions useful for treating disorders related to KIT, U.S. Pat., US2015/0111887A1, 2015.

17 (a) Y. Kubo, M. Suto, T. Araki, P. H. Mazzocchi, L. Klingler, D. Shook and C. Somich, J. Org. Chem., 1986, 51, 4404-4411; (b) J. Xue, Y. Zhang, T. Wu, H.-K. Fun and J.-H. Xu, J. Chem. Soc., Perkin Trans. 1, 2001, 183-191; (c) K. Matsumura, T. Mori and Y. Inoue, J. Org. Chem., 2010, 75, 5461-5469; (d) K. A. Rykaczewski and C. S. Schindler, Org. Lett., 2020, 22, 6516-6519.

18 R. A. Croft, J. J. Mousseau, C. Choi and J. A. Bull, Chem. Eur. J., 2016, 22, 16271-16276.

19 (a) R. A. Croft, J. J. Mousseau, C. Choi and J. A. Bull, Tetrahedron, 2018, 74, 5427-5435; (b) R. A. Croft, M. A. J. 
Dubois, A. J. Boddy, C. Denis, A. Lazaridou, A. S. VoisinChiret, R. Bureau, C. Choi, J. J. Mousseau and J. A. Bull, Eur. J. Org. Chem., 2019, 2019, 5385-5395; (c) M. A. J. Dubois, M. A. Smith, A. J. P. White, A. L. W. Jie, J. J. Mousseau, C. Choi and J. A. Bull, Org. Lett., 2020, 22, 5279-5283; For azetidines: (d) C. Denis, M. A. J. Dubois, A. S. Voisin-Chiret, R. Bureau, C. Choi, J. J. Mousseau and J. A. Bull, Org. Lett., 2019, 21, 300-304.

20 (a) C. A. Lipinski, F. Lombardo, B. W. Dominy and P. J. Feeney, Adv. Drug Delivery Rev., 1997, 23, 3-25; (b) C. W. Murray and D. C. Rees, Angew. Chem., Int. Ed., 2016, 55, 488-492; (c) A. Nadin, C. Hattotuwagama and I. Churcher, Angew. Chem., Int. Ed., 2012, 51, 1114-1122.
21 This outcome was consistent with a study by Zhang and Rao on silica gel mediated Friedel-Crafts alkylation of 3-indolylmethanols: Y. Zou, C. Chen, X. Chen, X. Zhang and W. Rao, Eur. J. Org. Chem., 2017, 2266-2271.

22 For development of $\mathrm{CaNTf}_{2} / \mathrm{BuNPF}_{6}$ catalysts: M. Niggemann and M. J. Meel, Angew. Chem., Int. Ed., 2010, 49, 3684-3687.

23 For possible routes to assess H-bonding potential: K. R. Francisco, C. Varricchio, T. J. Paniak, M. C. Kozlowski, A. Brancale and C. Ballatore, Eur. J. Med. Chem., 2021, 218, 113399.

24 Despite the low aqueous solubility of these compounds there were no precipitate alerts from DMSO providing high confidence in the data obtained. 